\title{
Anopheles stephensi Dual Oxidase Silencing Activates the Thioester-Containing Protein 1 Pathway to Suppress Plasmodium Development
}

\author{
Parik Kakani ${ }^{a}$ Mithilesh Kajla ${ }^{a, b}$ Tania Pal Choudhury ${ }^{a}$ Lalita Gupta ${ }^{a}$ c \\ Sanjeev Kumar ${ }^{\mathrm{a}, \mathrm{d}}$ \\ ${ }^{a}$ Molecular Parasitology and Vector Biology Laboratory, Department of Biological Sciences, Birla Institute of \\ Technology and Science, Vidya Vihar Campus, Pilani, India; ${ }^{b}$ National Institute of Malaria Research, New Delhi, India; \\ 'Department of Zoology, Chaudhary Bansi Lal University, Bhiwani, India; ${ }^{\mathrm{d}}$ Department of Biotechnology, Chaudhary \\ Bansi Lal University, Bhiwani, India
}

\section{Keywords}

Anopheles stephensi · Dual oxidase · Midgut · Plasmodium · Innate immunity · Thioester-containing protein $1 \cdot$ Malaria

\begin{abstract}
We characterized the dual oxidase (Duox) gene in the major Indian malaria vector Anopheles stephensi, which regulates the generation of reactive oxygen species. The AsDuox gene encodes for a 1,475-amino-acid transmembrane protein that contains an $\mathrm{N}$-terminal noncytoplasmic heme peroxidase domain, a calcium-binding domain, seven transmembrane domains, and a C-terminal cytoplasmic NADPH domain. Phylogenetic analyses revealed that $A$. stephensi Duox protein is highly conserved and shares $97-100 \%$ amino acid identity with other anopheline Duoxes. AsDuox is expressed in all the developmental stages of $A$. stephensi and the pupal stages revealed relatively higher expressions. The Duox gene is induced in Plasmodium-infected mosquito midguts, and RNA interference-mediated silencing of this gene suppressed parasite development through activation of the thioestercontaining protein 1 pathway. We propose that this highly conserved anopheline Duox, being a Plasmodium agonist, is an excellent target to control malaria parasite development inside the insect host.

(c) 2019 The Author(s)

Published by S. Karger AG, Basel
\end{abstract}

\section{KARGER}

E-Mail karger@karger.com www.karger.com/jin (c) 2019 The Author(s) Karger
Published by S. Karger AG, Basel Open access
This article is licensed under the Creative Commons AttributionNonCommercial-NoDerivatives 4.0 International License (CC BYNC-ND) (http://www.karger.com/Services/OpenAccessLicense). Usage and distribution for commercial purposes as well as any distribution of modified material requires written permission.

\section{Introduction}

Anopheles mosquitoes transmit Plasmodium, the parasite that causes malaria in humans. Although mosquito innate immunity is capable of controlling numerous microbial infections, the malaria parasite has developed some specific strategies to escape the mosquito immune barriers. Our understanding to these immune escaping mechanisms will help control Plasmodium development and block the insect cycle of malaria.

One of the most important mechanisms of mosquito innate immunity is centered on the production of reactive oxygen species (ROS) such as superoxides $\left(\mathrm{O}_{2}{ }^{\bullet-}\right)$, hydrogen peroxide $\left(\mathrm{H}_{2} \mathrm{O}_{2}\right)$, and hydroxyl radicals $(\bullet \mathrm{OH})$. ROS produces an oxidative stress that kills bacterial and fungal pathogens or causes melanization, encapsulation, or lysis of parasites [1-4]. These ROS are mostly generated by the NADPH oxidase (NOX) or dual oxidase (Duox) family of proteins $[1,2]$. The NOX/Duox family of proteins has $\mathrm{NADPH}-$, FAD-, and heme-binding sites and six transmembrane domains (TMs) [5]. Moreover, Duox has an additional heme peroxidase domain, a TM, and EF-hand motifs $[1,2,6]$.

A number of research reports revealed the role of Duox-generated ROS in insect immunity [1-4]. In Dro-

Prof. Sanjeev Kumar

Department of Biotechnology, Chaudhary Bansi Lal University Opposite-Education Board, B T M Colony

Bhiwani, Haryana 127021 (India)

E-Mail sanjeevnih@gmail.com 
sophila midgut, the ROS generated by DmDuox is utilized by its own peroxidase to produce an array of antimicrobial agents [1]. The knockout of the DmDuox gene increased bacterial growth and mortality in Drosophila [2]. Studies carried out in the African malaria vector Anopheles gambiae also revealed that higher levels of ROS enhance antibacterial and antiplasmodial immunity $[3,4]$. In addition to their immune role, insect Duoxes are also documented in various other biological functions including the cross-linking of extracellular matrix and tissue biogenesis. Accordingly, A. gambiae AgDuox cross-links the mucin layer on the luminal side of the midgut epithelium. This cross-linked barrier decreases midgut permeability to immune activators and thus suppresses mosquito immunity to support the growth of endogenous microbiota and Plasmodium [7].

Thus, we hypothesized that Duox, being an agonist to Plasmodium, might be considered a crucial target to block parasite development inside the mosquito midgut. Moreover, such vaccine candidates should have conserved sequence and function, at least, in major malaria vectors for widespread control of the disease. It is also important to mention that merely on the basis of sequence similarity, sometimes the function of a gene may not be predicted in different species of a genus, as reported in the case of several mosquito genes. For example, the silencing of the leucine-rich repeat-containing protein 1 gene in A. gambiae increased Plasmodium berghei infection, and it had no effect in the Anopheles stephensi-Plasmodium yoelii system [8]. In addition, the apolipophorin III gene is an antagonist to Plasmodium development in A. gambiae and an agonist in $A$. stephensi, although it has high sequence similarity in case of both mosquitoes [9]. Accordingly, it is necessary to analyze the function of important immune molecules in major malaria vectors to identify a novel vaccine candidate. In the present study, the Duox gene was characterized in the major Indian malaria vector $A$. stephensi, and its role in the regulation of antiplasmodial immunity was analyzed.

\section{Materials and Methods}

\section{Rearing of Mosquitoes}

A. stephensi mosquitoes were reared in an insectory at $28^{\circ} \mathrm{C}$, $80 \%$ relative humidity, and a 12-h light:dark cycle as described before $[9,10]$. Adult mosquitoes were regularly allowed to take $10 \%$ sucrose solution. For colony propagation, 4- to 5-day-old females were fed on anesthetized mice and their eggs were collected in moist condition $[11,12]$. The hatched larvae were floated in water and fed on a 1:1 mixture of dog food (Pet Lover's, India) and fish food (Gold Tokyo, India).

Mosquito Duox Is Agonistic to

Plasmodium
Retrieval of the AsDuox Gene from the A. stephensi Genome

We retrieved the Duox gene in the partially annotated genome of A. stephensi (taxId: 30069) using the A. gambiae AgDuox gene (AGAP009978) as a reference. For that, the AgDuox gene sequence was BLAST searched against the A. stephensi genome, and the best hit contig 2339 (Super Contig KB664518 and Ensembl identifier ASTE003295) was analyzed using the Augustus software to identify the putative 9.45-kb-long AsDuox gene.

Plasmodium Infection of A. stephensi Mosquitoes

For infection, 4- to 5-day-old female mosquitoes starved overnight were fed on an anesthetized Swiss albino mouse that was already infected with GFP-expressing $P$. berghei (transgenic $\mathrm{PbGFP}$ ). The blood-fed females were maintained at $21^{\circ} \mathrm{C}$, which is a permissive temperature for $P$. berghei development $[9,13]$. The mosquitoes fed on an uninfected mouse served as controls. Mosquito midguts were dissected in Ashburner's PBS ( $3 \mathrm{~mm}$ sodium chloride, $7 \mathrm{~mm}$ disodium hydrogen phosphate, and $3 \mathrm{~mm}$ sodium dihydrogen phosphate, $\mathrm{pH}$ 7.2) at different time points post feeding and stored at $-80^{\circ} \mathrm{C}$ in RNAlater (Qiagen). Sugar-fed mosquito midguts were also collected in a similar way. Further, RNA was isolated and relative mRNA levels of different genes were quantified using the qPCR method as described in the online supplementary methods (for all online suppl. material, see www. karger.com/doi/10.1159/000497417).

Analyzing the Effect of AsDuox Gene Silencing on Plasmodium Development

Two-day-old female mosquitoes were injected with $69 \mathrm{~nL}$ of dsLacZ (controls) or dsAsDuox (silenced) RNA into their thorax using a nanojector (Drummond, USA). Four days after injection, mosquitoes were allowed to feed on mice infected with GFP-expressing $P$. berghei. Seven days post Plasmodium infection, mosquito midguts were dissected in Ashburner's PBS, fixed in 4\% paraformaldehyde, and the number of fluorescent oocysts was counted in individual midguts as described before $[9,13]$.

\section{Results}

\section{Retrieval and Cloning of the AsDuox Gene}

We analyzed $A$. stephensi contig 2339 to retrieve the fulllength AsDuox gene using the Augustus software. This gene has an open reading frame of $4,428 \mathrm{bp}$ that encodes for a 1,475-amino-acid protein (online suppl. Fig. S1). In addition, the $5^{\prime}$ - and $3^{\prime}$-untranslated regions were predicted to be 165 and $1,116 \mathrm{bp}$, respectively. The signal for polyadenylation, ATTTA, is located 964 bp downstream from the stop codon. Furthermore, the analysis of the AsDuox promoter region by the JASPAR and MatInspector softwares revealed the binding sites for numerous transcription factors such as ecdysone-induced E74A transcription factor, GATA, and ATF-2 (online suppl. Fig. S1). The presence of these transcription factor binding sites suggested a tissue-specific expression and immune role of AsDuox, as described in the case of numerous other genes [1, 14-17].

J Innate Immun 2019;11:496-505 


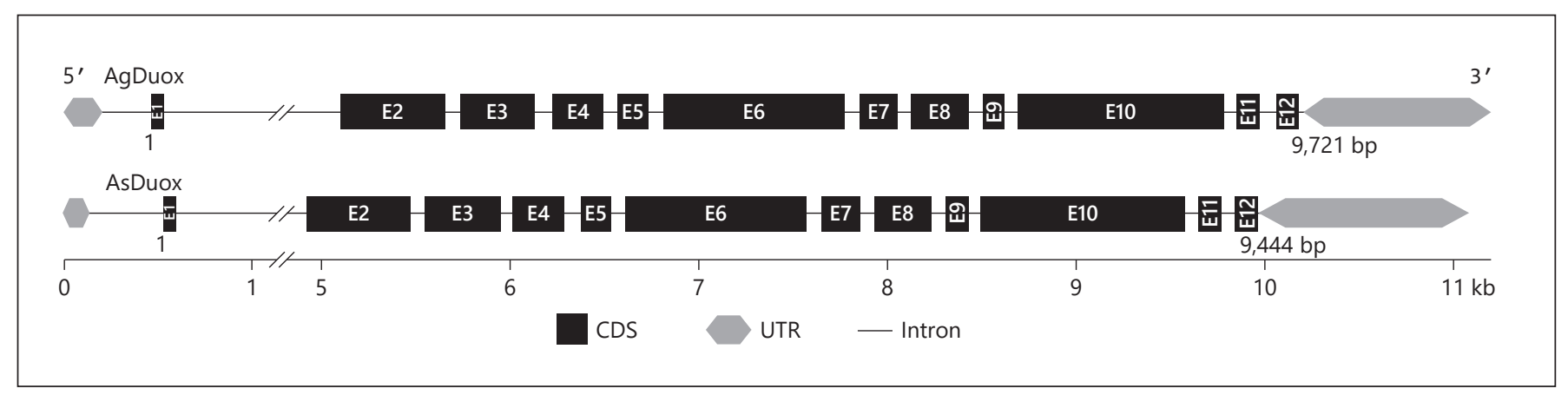

Fig. 1. Genomic organization of the Duox gene in A. gambiae and A. stephensi. Both A. gambiae (AgDuox) and A. stephensi (AsDuox) genes have 12 exons and 11 introns. The AgDuox gene is 9,721 bp, while the AsDuox gene is 9,444 bp, and both of the genes have an open reading frame of $4,428 \mathrm{bp}$. The $5^{\prime}$ and $3^{\prime}$ UTRs of the AgDuox gene are 268 and 1,016 bp, respectively. However, the $5^{\prime}$ and $3^{\prime}$ UTRs of the AsDuox gene are 165 and 1,116 bp, respectively. Numbers represent the first base of start codon or last base of stop codons in the AgDuox and AsDuox genes. Duox, dual oxidase, UTR, untranslated region.
The A. stephensi cDNA template was used to amplify a partial gene segment and the full-length AsDuox gene (online suppl. Fig. S2) using primer sets F1R1 and F7R6, respectively, as listed in online supplementary Table S1. PCR products for the partial gene clone $(\sim 400 \mathrm{bp})$ and the full-length AsDuox gene $(\sim 5 \mathrm{~kb})$ were sequenced, and BLAST results revealed that they both had the closest match to the A. gambiae AgDuox (AGAP0099778) gene. These results confirmed the presence of the Duox gene in A. stephensi genome. The full-length AsDuox gene sequence was submitted to the NCBI GenBank database and an accession number KY386660 was obtained. The alignment of full-length cDNA sequence KY386660 with the predicted AsDuox gene revealed that it is organized into 12 exons and 11 introns in a way similar to the $A$. gambiae AgDuox gene (Fig. 1).

\section{Domain Structure and Organization of the AsDuox \\ Protein}

Comparison of the AsDuox protein with other insect Duoxes using the SMART program revealed that the Nterminal of this protein has a heme peroxidase domain (7-528 residue) as well as a calcium-binding domain that contains three EF-hand motifs in a helix-loop-helix topology (from 797-825, 833-861, and 878-906 residue, respectively). In addition, ferric reductase domain (1010-1157 residue), FAD-binding domain (1193-1294 residue), and NAD-binding domain (1300-1456 residue) were also identified in the AsDuox protein (Fig. 2a). Furthermore, Phobius software-based analysis also revealed the presence of seven TMs in the AsDuox protein that are arranged in two different regions, one TM between the peroxidase and calcium binding domains and another six TMs between calcium binding domain and NOX domain (from 566588, 968-988, 1000-1025, 1055-1076, 1106-1129, 11411162 , and $1168-1187$ residue, respectively) (Fig. 2a, b). In addition, the Conserved Domain Database analysis also revealed the presence of 12 heme-, 14 substrate-, and $19 \mathrm{cal}$ cium-binding sites in the AsDuox protein (online suppl. Fig. S3). This domain organization of the AsDuox protein corroborates with the domain structure of other Duoxes such as Aedes aegypti AaDuox (XP_001658452.1), Bombyx mori BmDuox (JQ768349), Marsupenaeus japonicus MjDuox1 (AB744213.1) and MjDuox2 (ANA91274.1), Danio rerio DrDuox (BAF33370.1), and Homo sapiens HsDuox1 (NP_054799.4) and HsDuox2 (NP_059130.2) $[4,18-20]$. In addition, the N-terminal heme peroxidase domain of the AsDuox protein is noncytoplasmic, whereas the C-terminal NOX domain is cytoplasmic (Fig. 2b) in a way similar to Drosophila and human Duoxes [19, 21]. Interestingly, the heme peroxidase domain and the NOX domain of the AsDuox protein shared 27 and $76 \%$ identity, respectively with the corresponding domains of human Duoxes (online suppl. Table S2). This showed that the heme peroxidase domain of human Duoxes is more diverged from AsDuox in comparison to the NOX domain. These findings are in agreement with the previously reported B. mori BmDuox in which the peroxidase domain shared only $42 \%$ identity with the peroxidase domain of human Duoxes [18]. The three-dimensional structure of the AsDuox protein was modeled using the RaptorX software. Interestingly, the domain structure of the AsDuox protein (Fig. 2c) is similar to the three-dimensional structure of kuruma shrimp M. japonicus MjDuox1 [20]. 


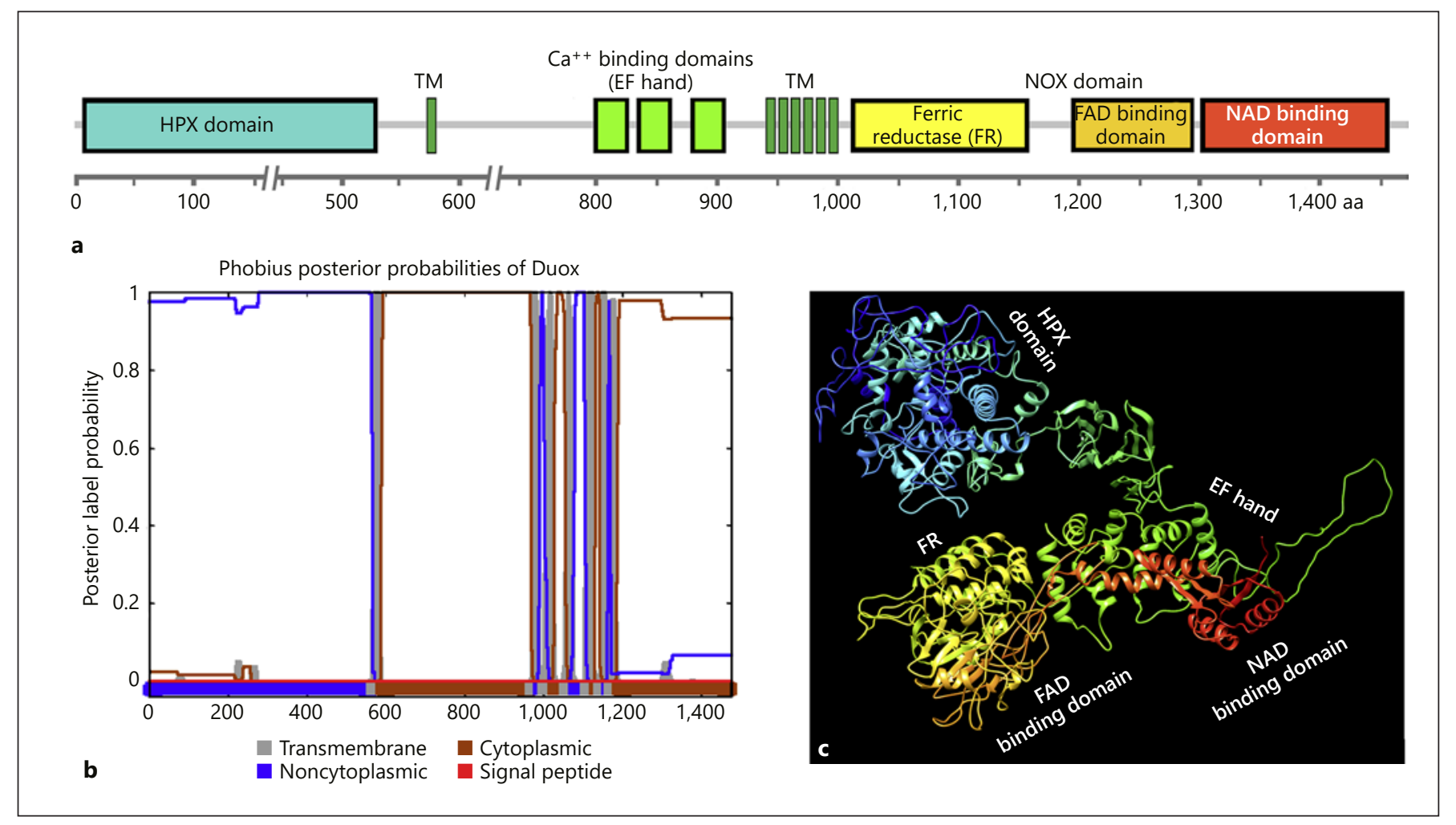

Fig. 2. Domain organization of the AsDuox protein. a Schematic view of different domains present in the AsDuox protein. It contains an N-terminal heme peroxidase region, putative TMs (one near the peroxidase domain and another six near the NOX domain), EF hand, calcium binding sites and an NOX domain at the C-terminal. b Analysis of AsDuox protein topology. The AsDuox protein contains seven putative TMs as shown in gray color. The $\mathrm{N}$-terminal is noncytoplasmic (blue color) while the C-termi-

\section{Phylogenetic Analysis of the AsDuox Protein}

Presence of the Duox gene is reported from lower to higher eukaryotic organisms [22]. Consequently, it is important to study the sequence conserveness and divergence of AsDuox with other animal Duoxes, including human Duoxes. Thus, the phylogenetic analyses of AsDuox protein with other animal Duoxes was carried out as discussed in the online supplementary methods. The alignment of full-length AsDuox protein (KY386660) with other well-characterized Duoxes (as mentioned in online suppl. Table S3) from invertebrates (arthropods and nematodes) and vertebrates (primates, Rodentia, Chiroptera, Artiodactyla) revealed that it shared 99, 94, and $93 \%$ identity with A. gambiae, Ae. aegypti, and Culex quinquefasciatus Duoxes, respectively. In addition, it shared $>70 \%$ and $<40 \%$ similarity with insects and human Duoxes, respectively (online suppl. Table S3). Phy- nal is cytoplasmic (brown color). c Three-dimensional model of AsDuox. The HPX domain is highlighted blue and the EF hand green. The NOX homology domain contains ferric reductase (greenish yellow), an FAD-binding domain (golden yellow), and an NAD-binding domain (red). The three-dimensional structure was predicted using the RaptorX software. Duox, dual oxidase; HPX, heme peroxidase; NOX, NADPH oxidase; TM, transmembrane domain. logenetic analysis of selected vertebrate and invertebrate Duoxes using the MEGA 5.2 program revealed that they are separated into two major clades (online suppl. Fig. S4). The cluster of arthropods was further divided into four major subclusters that include the Duoxes from Crustacean, Hymenoptera, Lepidoptera, and Diptera. Drosophila and mosquito (Anopheles, Aedes, and Culex) Duoxes appeared in a single cluster of the order Diptera. The major cluster of vertebrate Duoxes is further divided into the two subclusters Duox1 and Duox2 (online suppl. Fig. S4). In conclusion, the AsDuox protein was found to be clustered with Dipteran Duoxes and is far diverged from vertebrate Duoxes.

In general, essential genes that play a crucial role in the life of an organism remained highly conserved during evolution [23]. Thus, we analyzed the functional conservation among Duox proteins of seventeen anophelines 
Fig. 3. Developmental stages and body compartment-specific expression of the AsDuox gene. a Relative mRNA levels of the AsDuox gene in different developmental stages of $A$. stephensi. The mRNA levels in eggs were considered as control or 1.0. Significant differences in the relative mRNA levels of different stages against controls are indicated by asterisks $\left({ }^{* *} p<\right.$ $0.01, * * * p<0.001)$. b Relative mRNA levels of the AsDuox gene were analyzed in midguts and carcasses of sugar-fed $(0 \mathrm{~h})$ or $24 \mathrm{~h}$ post blood-fed mosquitoes. The mRNA levels of sugar-fed midgut were considered as control or 1.0. Significant differences are indicated by asterisks $(* * p<$ $0.01)$. The results are represented as the mean \pm standard deviation of three experiments. Duox, dual oxidase.

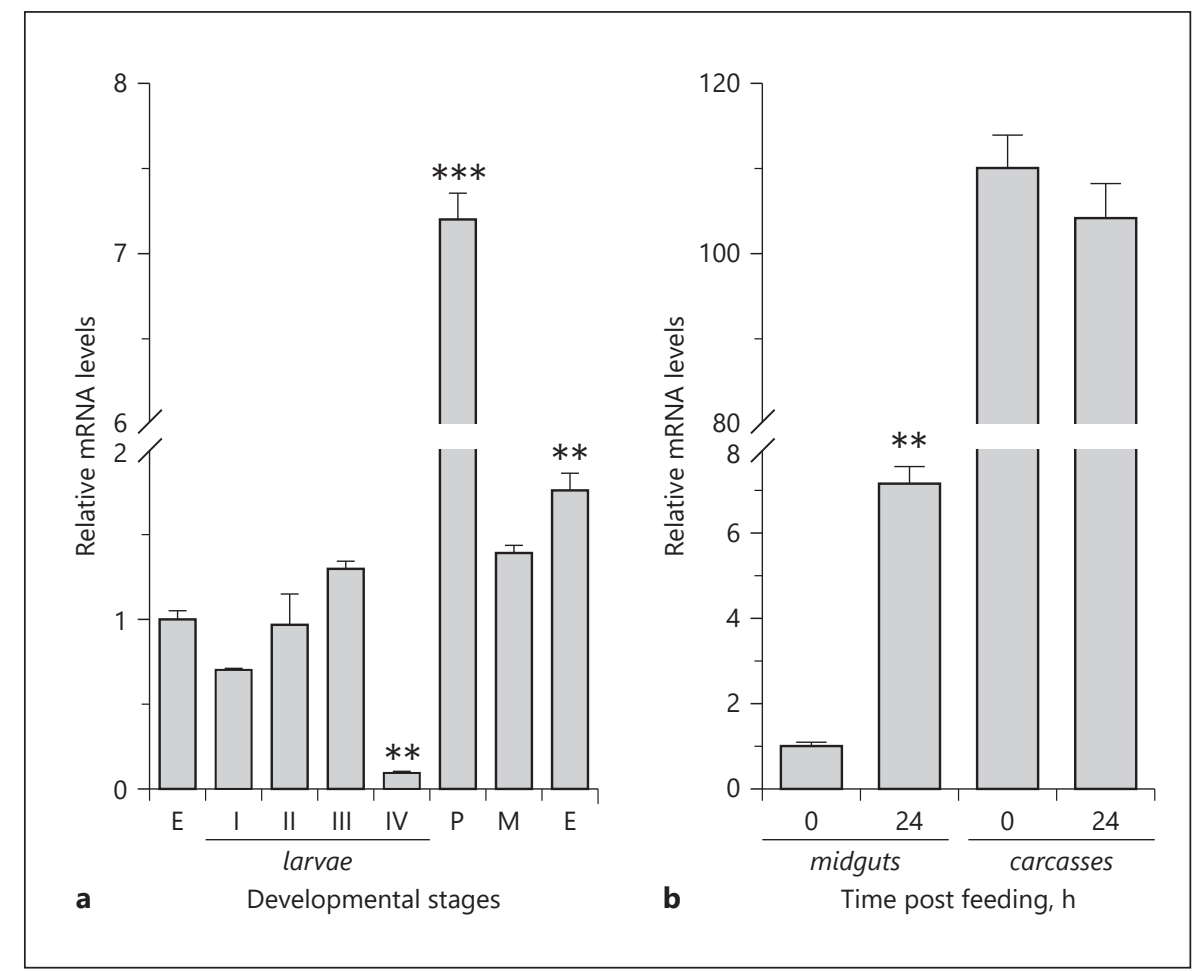

distributed worldwide [24] as described in the online supplementary methods. Interestingly, the Duox protein from each anopheline was found to be 1,475 amino acids long and collectively they are highly conserved with 97$100 \%$ identity (online suppl. Tables S4 and S5). These observations suggested that anopheline Duoxes might regulate similar biological processes as reported in the case of other mosquito peroxidases $[7,25,26]$, and therefore it might be considered a common target for widespread control of malaria vectors.

Furthermore, to analyze the evolutionary relationship between Duox proteins of anophelines distributed worldwide, we constructed a phylogenetic tree as shown in online supplementary Figure S5. Interestingly, the phylogenetic relationship of anopheline Duoxes followed a pattern similar to the evolutionary classification of these mosquitoes, as described earlier (Fig. 1 of Neafsey et al. [24]). These results revealed that the Duox gene is conserved among anophelines and also evolved in a way similar to the evolution of these mosquitoes.

\section{The AsDuox Gene Is Expressed in Different Stages of Mosquito Development}

To understand the functionality of the AsDuox gene, we analyzed its expression in different developmental stages of A. stephensi mosquitoes, namely eggs, larvae, pupae, and adults. The result presented in Figure 3 a revealed that the AsDuox gene is expressed in all developmental stages of mosquitoes. Interestingly, the relative mRNA levels of the AsDuox gene were similar in eggs and the first three stages of instar larvae (1st instar to 3rd instar larvae). Since the transition between different larval stages depends on the formation of a new extracellular cuticle layer $[27,28]$, the expression patterns of the AsDuox gene are in agreement as reported in other organisms $[29,30]$.

Furthermore, AsDuox mRNA levels were downregulated 10 -fold in 4th instar larvae $(p=0.0015)$ and upregulated 7 -fold in the pupal stages of development $(p=$ 0.0004 ) when compared to the eggs (Fig. 3a). The expression pattern of the AsDuox gene in 4th instar larvae and pupae corresponds to the decreased or increased levels of ecdysone hormone, respectively as reported in case of Drosophila and Ae aegypti [28, 31, 32]. The presence of ecdysone-induced E74A transcription factor binding site in the promoter region of the AsDuox gene (online suppl. Fig. S1) strengthens these observations in a way similar to other ecdysone-induced genes in Drosophila [33]. Hence, the overall expression of the AsDuox gene during developmental stages of $A$. stephensi suggested its important role in mosquito development. 


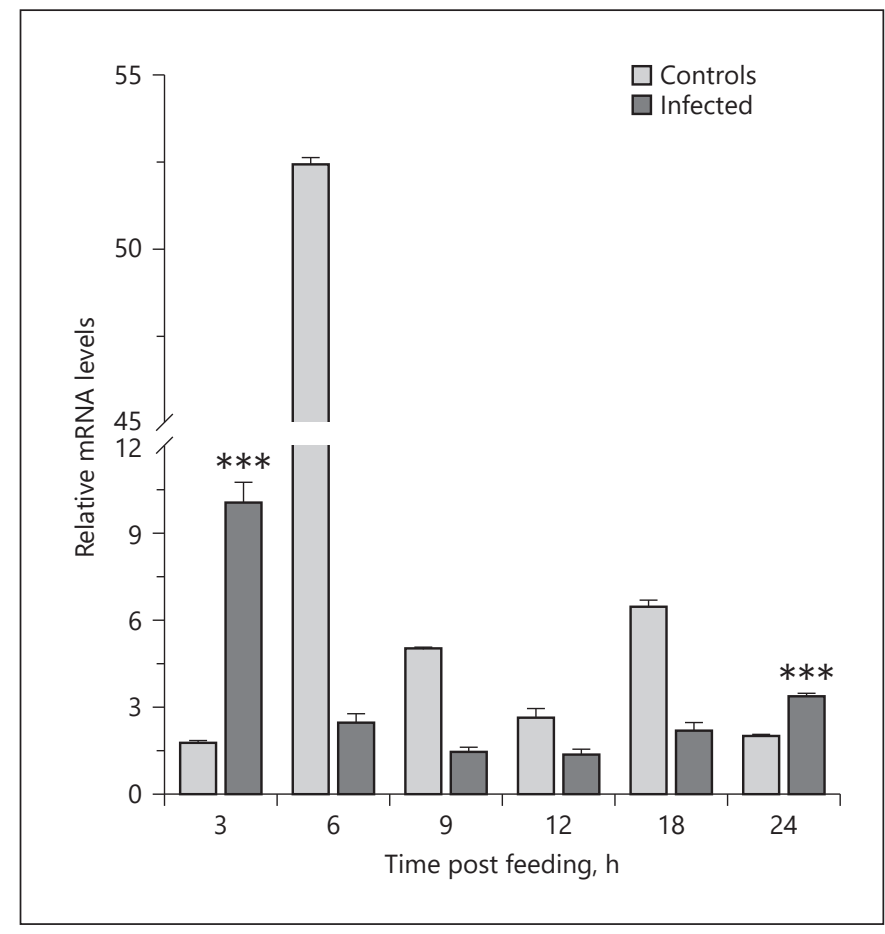

Fig. 4. Expression kinetics of the AsDuox gene in P. berghei-infected midguts. The relative mRNA levels (mean \pm standard deviation) of AsDuox gene were analyzed at different time points after uninfected (controls) or P. berghei-infected (infected) blood feeding. The relative fold induction was calculated against sugar-fed midguts. Significant differences (upregulation) between control and infected midgut mRNA levels are indicated by asterisks $(* * * p<$ 0.001). Error bars represent the standard deviation of measurements calculated from replicates $(n=3)$. Duox, dual oxidase.

Blood Feeding Induced Mosquito Body CompartmentSpecific Expression of the AsDuox Gene

The effect of blood feeding on the expression pattern of the AsDuox gene was analyzed in different body compartments of mosquitoes. For that, we compared the relative mRNA levels of the AsDuox gene in sugar- or blood-fed mosquito midguts and carcasses. In sugar-fed mosquitoes, the relative mRNA levels of the AsDuox gene were 110-fold higher in carcasses than midguts ( $p=$ 0.0024 , Fig. 3b). Furthermore, the AsDuox mRNA levels were upregulated 7 -fold in $24 \mathrm{~h}$ post blood-fed midguts against sugar-fed controls $(p=0.002)$. However, there was no significant difference in AsDuox mRNA levels in sugar- or blood-fed carcasses ( $p=0.464$, Fig. $3 b$ ). These results revealed the compartment-specific induction of the AsDuox gene in blood-fed mosquitoes. In general, suchlike expression of a gene is controlled by some specific transcription factors. For example, the transcription factor GATA drives tissue-specific expression of the trypsin and hexamerin genes in mosquito and of the diptericin gene in Drosophila [14-16]. The presence of a GATA-binding site in the regulatory region of the AsDuox gene (online suppl. Fig. S1) elucidated the tissue-specific expression of the AsDuox gene (Fig. 3b). In addition, the presence of ecdysone-induced E74A transcription factor binding site in the regulatory region of the AsDuox gene (online suppl. Fig. S1) also explained its regulation by ecdysone hormone, which is induced in blood-fed mosquitoes as reported elsewhere [17, 31, 33, 34].

Plasmodium Ookinete Invasion Induced Expression of the AsDuox Gene

We analyzed expression of the AsDuox gene during midgut stage of Plasmodium development. For that, the kinetics of AsDuox gene expression was analyzed in uninfected or $P$. berghei-infected blood-fed mosquito midguts. AsDuox mRNA levels were induced 52-fold in $6 \mathrm{~h}$ post uninfected blood-fed midguts against sugar-fed midguts ( $p=0.0017$, Fig. 4 ). This early induction of the AsDuox gene is in accordance with the transient growth of midgut bacteria in blood-fed mosquitoes as reported before [35-38]. Interestingly, at $3 \mathrm{~h}$ post feeding, expression of the AsDuox gene was induced 7-fold in P. bergheiinfected midguts against uninfected blood-fed controls $(p=0.0017)$, which indicated recognition of Plasmodium developmental stages by the mosquito immunity. These observations are in agreement with other studies where important mosquito immune genes were reported to be induced against early stages of Plasmodium development $[39,40]$.

Furthermore, 6-18 h post feeding, expression of the AsDuox gene was downregulated in Plasmodium-infected midguts against their respective controls (Fig. 4). The reduced expression of the AsDuox gene in infected midguts appears to circumvent the lethal effect of Duox-generated ROS by Plasmodium as reported earlier [4, 41, 42]. For example, Plasmodium upregulates the expression of numerous ROS detoxification enzymes in A. gambiae to support its survival [4]. In addition, Leishmania also evades the ROS responses to ensure its survival within the insect or mammalian host [41, 42]. In conclusion, manipulation of host oxidative response is one of the common strategies behind the success of parasite development.

Interestingly, the induction of AsDuox gene in $24 \mathrm{~h}$ Plasmodium-infected midguts against controls $(p=$ 0.0036 , Fig. 4 ) is in agreement with previous findings, 
Fig. 5. AsDuox silencing in midgut suppressed $P$. berghei development. a Relative mRNA levels (mean \pm standard deviation) of the AsDuox gene in dsLacZ (unsilenced controls) or dsAsDuox (silenced) RNA injected and $24 \mathrm{~h}$ post $P$. berghei-infected midguts were analyzed. Asterisks indicate the significant difference between controls and silenced midguts $\left({ }^{* *} p<0.01\right)$. b Effect of midgut AsDuox silencing on the number of live oocysts (green dots) seven days post $P$. berghei infection. Horizontal lines indicate median number of parasites with $p<0.0001$ as calculated by the Kolmogorov-Smirnov test. The experiment was performed in triplicates. Duox, dual oxidase; $n$, number of mosquitoes.

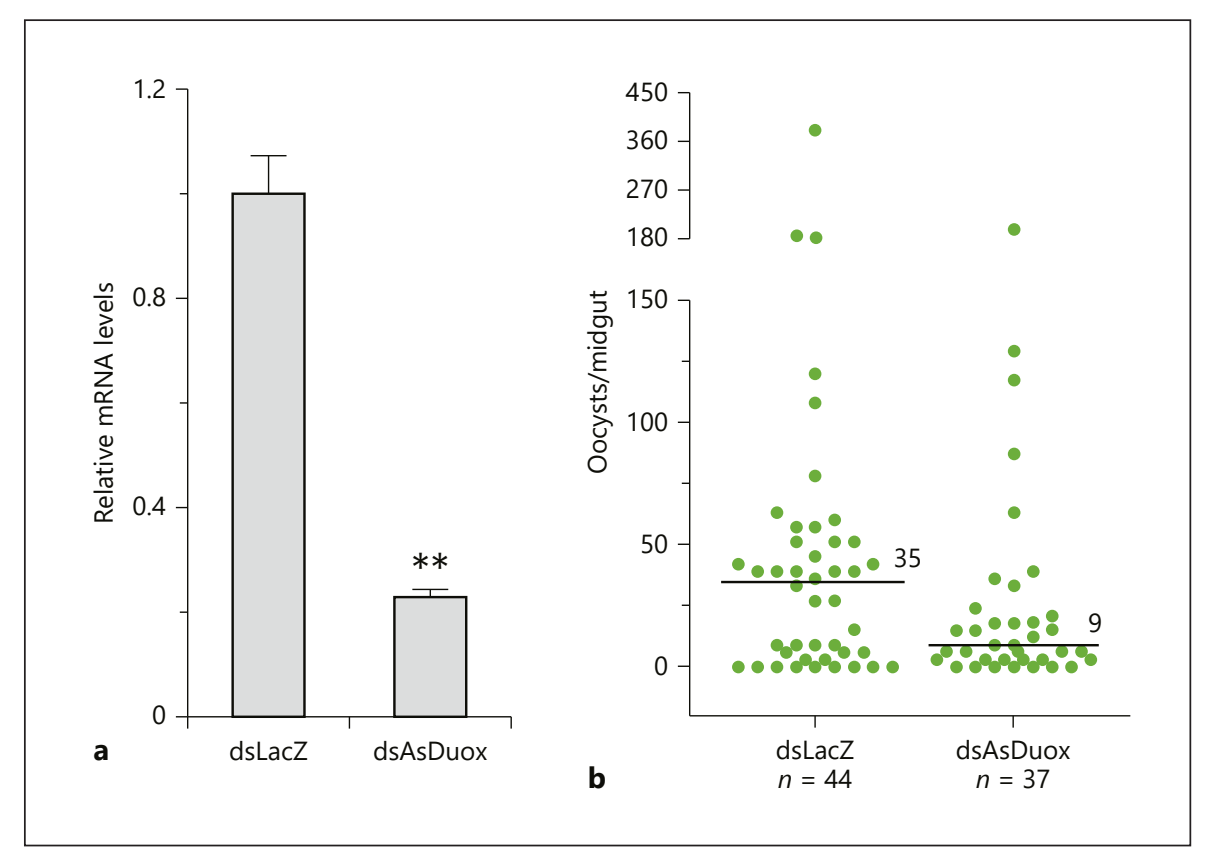

where we observed that ROS regulates the numbers of ookinetes that traverse the mosquito midgut epithelium $[4,13]$.

AsDuox Silencing Reduced Plasmodium Development

To explore the role of AsDuox in the regulation of midgut stages of Plasmodium development, the gene was silenced through RNA interference as discussed in Materials and Methods, and its effect on developing oocysts was evaluated 7 days post infection. The relative levels of AsDuox mRNA in controls and silenced midguts revealed $80 \%$ silencing of this gene ( $p=0.0002$, Fig. $5 a)$. We observed variable numbers of oocysts in control and silenced midguts due to individual variations. However, the median oocysts number in controls and AsDuox silenced midguts was 35 and 9 , respectively $(p<0.0001$, Fig. 5b). These results revealed that AsDuox gene silencing reduced the oocysts number significantly, and thus it is an agonist for Plasmodium development. These results are in agreement with a previous study where the silencing of the AsDuox ortholog also reduced the Plasmodium oocysts number in A. gambiae [7].

To understand the mechanism of AsDuox silencingmediated reduction in oocyst numbers, we analyzed the regulation of well-known antiplasmodial genes, thioester-containing protein 1 (TEP1) and nitric oxide synthase (NOS) $[7,38,43,44]$, in the midguts mentioned in Figure 5a. The results presented in Figure 6 revealed that the relative mRNA levels of TEP1 gene were induced 3-fold in AsDuox silenced midguts against controls $(p=0.0002)$. Moreover, the mRNA levels of NOS gene were reduced 2 -fold in the silenced midguts when compared to the controls $(p=0.005)$. These findings suggested that the induced TEP1 is one of the major pathways that demonstrate an antiplasmodial effect in AsDuox silenced midguts.

\section{Discussion}

In the present study, we characterized A. stephensi Duox gene that encodes for a 1,475-amino-acids long transmembrane protein. The AsDuox protein shared 97100\% identity with Duoxes from 17 other anophelines distributed worldwide; however, it is diverged $(<40 \%$ identity) from vertebrate Duoxes. Structural analysis revealed that the $\mathrm{N}$-terminus of the AsDuox protein is noncytoplasmic and contains a heme peroxidase domain and a calcium-binding domain. The C-terminus being cytoplasmic is an NOX that contains FAD- and NAD-binding domains (Fig. 2). The structural organization and sequence of AsDuox domains (Fig. 2; online suppl. Fig. S3) are similar to other Duoxes $[6,18,19]$.

AsDuox is expressed in the eggs and the first three stages of the instar larvae to ensure proper biogenesis of extracellular cuticle layer during eclosion in a way simi- 


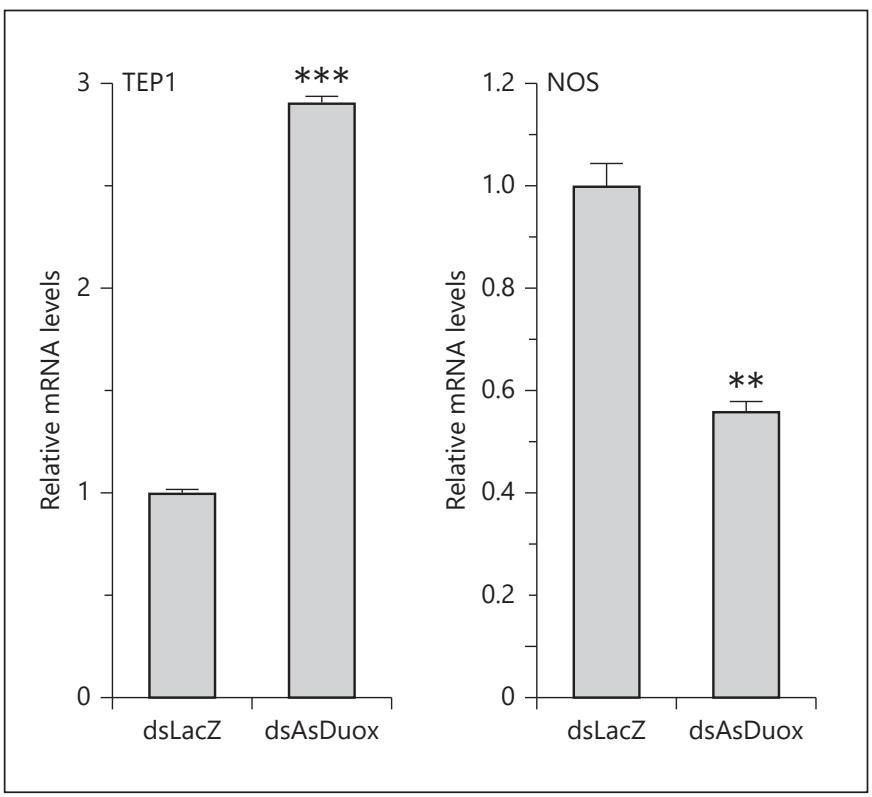

Fig. 6. TEP1 is induced in AsDuox silenced P. berghei-infected $A$. stephensi midguts. Relative mRNA levels (mean \pm standard deviation) of TEP1 or NOS gene were analyzed in dsLacZ (unsilenced controls) or dsAsDuox (silenced) RNA injected $P$. berghei-infected blood-fed midguts at $24 \mathrm{~h}$ post feeding. Control midguts were taken as 1.0. Significant differences between controls and silenced midguts are shown by asterisks $\left({ }^{* *} p<0.01,{ }^{* * *} p<0.001\right)$. Error bars represent standard deviation $(n=3)$. Duox, dual oxidase; NOS, nitric oxide synthase; TEP1, thioester-containing protein 1 .

lar to Caenorhabditis elegans where CeDuox, an ortho$\log$ of AsDuox, catalyzes the cross-linking of collagen protein in extracellular matrix [29, 30]. Interestingly, downregulation of the AsDuox gene in 4th instar larvae (Fig. 3a) appears to reduce the cross-linking of extracellular matrix so that they can easily enter the pupal stage of development [28]. On the contrary, the induced expression of AsDuox gene in pupae (Fig. 3a) signifies its importance similar to other insects where ecdysone hormone regulates pupal development and metamorphosis $[31,32,45]$. For example, in Drosophila the gene named Curly Su (Cysu), which acts as Duox and has a binding site for ecdysone-induced BR-C transcription factor, stabilizes the cuticle and other exoskeletons during pupal development [31, 46-48]. The presence of an ecdysone binding site in the promoter region of the AsDuox gene (online suppl. Fig. S1) strengthens the above observations and suggests its crucial role in mosquito development.
Expression analysis of the Duox gene in P. bergheiinfected mosquitoes revealed its biphasic induction at $3 \mathrm{~h}$ (an early phase) and $24 \mathrm{~h}$ (a late phase) post infection against their respective controls (Fig. 4). An early induction of the AsDuox gene in infected midguts seems to be the part of antiplasmodial immunity in a way similar to other immune genes $[40,49-51]$. The late phase of AsDuox gene induction corroborates the time particularly when ookinetes invade the midgut epithelium. The ookinete invasion damages the midgut epithelium, which in turn increases the interaction of lumen bacteria with mosquito immunity $[13,40]$. Thus, induction of the AsDuox gene during ookinete invasion is likely to be the part of immune response against lumen bacteria (Fig. 4) and is in agreement with findings as reported in the case of A. gambiae [13]. Interestingly, expression of the AsDuox gene is downregulated in Plasmodium-infected midguts exclusively from 6 to $18 \mathrm{~h}$ post infection (Fig. 4), indicating active suppression of Duox-generated ROS by the parasite. Such immunosuppressive behaviors are commonly exhibited by Plasmodium as well as other parasites inside the insect or mammalian hosts $[3,4,41,42]$.

It is of note that blood feeding induces microbial growth in the midgut lumen [7, 35-37]. In addition, the increased levels of ecdysone hormone in blood-fed mosquito also induce an array of genes which are responsible to balance midgut immunity and physiology $[7,25,52]$. We found that two of the peroxidase genes that are induced in blood-fed A. stephensi mosquitoes are AsDuox (Fig. 3b) and AsHPX15, as reported in our previous publications $[25,26,38]$. Interestingly, in the case of A. gambiae AgDuox and AgHPX15, orthologs of the abovementioned A. stephensi peroxidases are also induced after blood feeding, and both of them regulate the cross-linking of mucins barrier over the midgut epithelium. This cross-linked mucins barrier blocks the interactions between luminal microbial antigens and mosquito midgut immunity [7]. Silencing of the A. gambiae AgDuox gene induced the NOS gene, which in turn killed Plasmodium $[7,47]$. In the present study, we also found that silencing of the AsDuox gene greatly reduced Plasmodium development (Fig. 5b), and this antiplasmodial effect was mediated through the induction of one of the major antiplasmodial molecules, TEP1 (Fig. 6). Conclusively, AsDuox silencing in A. stephensi suppressed Plasmodium development through induction of the TEP1 pathway, while in A. gambiae the antiplasmodial effect of AgDuox silencing is mediated through induction of the NOS pathway. Thus, the function of the Duox gene is conserved in both the anophelines, but there are subtle differences in the im- 
mune mechanism of these two major malaria vectors for the same outcome.

In conclusion, Duox seems to be an authentic Plasmodium agonist that shares $99-100 \%$ and $40 \%$ sequence similarity with anopheline and human Duoxes, respectively. This information can be further explored to generate novel sequence-specific transmission blocking antibodies to arrest Plasmodium development inside the malaria vectors.

\section{Acknowledgment}

The authors wish to thank the laboratory staff for maintaining the insectory, institute administration for providing all other facilities to accomplish the research, and central animal facilities for providing study animals.

\section{Statement of Ethics}

All procedures were approved by the Institutional Animal Ethics Committee. The authors have no ethical conflicts to disclose.

\section{Disclosure Statement}

The authors have no conflicts of interest to declare.

\section{Funding Sources}

This work was supported by research grants from the Department of Science and Technology, Government of India (grant number SR/SO/HS-0131/2010). P. Kakani and T.P. Choudhury would like to acknowledge the Department of Science and Technology, Government of India for providing the fellowship. University Grants Commission, India provided a Basic Science Research fellowship to M. Kajla.

\section{Author Contributions}

P. Kakani, L. Gupta, and S. Kumar designed the experiments for this work. P. Kakani, T.P. Choudhury, and M. Kajla collected the samples to perform the experiments. P. Kakani, T.P. Choudhury, M. Kajla, L. Gupta, and S. Kumar performed the expression kinetics of Duox. P. Kakani, L. Gupta, and S. Kumar performed the Duox silencing experiments. P. Kakani, L. Gupta, and S. Kumar analyzed the data and wrote the manuscript with input from all authors. All authors read and approved the manuscript.

\section{References}

1 Ha EM, Lee KA, Seo YY, Kim SH, Lim JH, Oh $\mathrm{BH}$, et al. Coordination of multiple dual oxidase-regulatory pathways in responses to commensal and infectious microbes in Drosophila gut. Nat Immunol. 2009 Sep;10(9): 949-57.

2 Ha EM, Oh CT, Bae YS, Lee WJ. A direct role for dual oxidase in Drosophila gut immunity. Science. 2005 Nov;310(5749):847-50.

3 Kumar S, Christophides GK, Cantera R, Charles B, Han YS, Meister S, et al. The role of reactive oxygen species on Plasmodium melanotic encapsulation in Anopheles gambiae. Proc Natl Acad Sci USA. 2003 Nov; 100(24):14139-44.

4 Molina-Cruz A, DeJong RJ, Charles B, Gupta L, Kumar S, Jaramillo-Gutierrez G, et al. Reactive oxygen species modulate Anopheles gambiae immunity against bacteria and Plasmodium. J Biol Chem. 2008 Feb;283(6):321723.

5 Bedard K, Krause KH. The NOX family of ROS-generating NADPH oxidases: physiology and pathophysiology. Physiol Rev. 2007 Jan;87(1):245-313.

6 Sumimoto H. Structure, regulation and evolution of Nox-family NADPH oxidases that produce reactive oxygen species. FEBS J. 2008 Jul;275(13):3249-77.

7 Kumar S, Molina-Cruz A, Gupta L, Rodrigues J, Barillas-Mury C. A peroxidase/dual oxidase system modulates midgut epithelial immuni- ty in Anopheles gambiae. Science. 2010 Mar; 327(5973):1644-8.

8 Jaramillo-Gutierrez G, Rodrigues J, Ndikuyeze G, Povelones M, Molina-Cruz A, Barillas-Mury C. Mosquito immune responses and compatibility between Plasmodium parasites and anopheline mosquitoes. BMC Microbiol. 2009 Jul;9(1):154.

9 Dhawan R, Gupta K, Kajla M, Kakani P, Choudhury TP, Kumar S, et al. Apolipophorin-III Acts as a Positive Regulator of Plasmodium Development in Anopheles stephensi. Front Physiol. 2017 Apr;8:185.

10 Kajla M, Bhattacharya K, Gupta K, Banerjee U, Kakani P, Gupta L, et al. Identification of the Temperature Induced Larvicidal Efficacy of Agave angustifolia against Aedes, Culex, and Anopheles Larvae. Front Public Health. 2016 Jan;3:286.

11 Day JF. Mosquito Oviposition Behavior and Vector Control. Insects. 2016 Nov;7(4):65.

12 Gupta K, Dhawan R, Kajla M, Misra T, Kumar S, Gupta L. The evolutionary divergence of STAT transcription factor in different Anopheles species. Gene. 2017 Jan;596:89-97.

13 Kumar S, Gupta L, Han YS, Barillas-Mury C. Inducible peroxidases mediate nitration of anopheles midgut cells undergoing apoptosis in response to Plasmodium invasion. J Biol Chem. 2004 Dec;279(51):53475-82.

14 Jinwal UK, Zakharkin SO, Litvinova OV, Jain $\mathrm{S}$, Benes H. Sex-, stage- and tissue-specific regulation by a mosquito hexamerin promoter. Insect Mol Biol. 2006 Jun;15(3):301-11.

15 Senger K, Harris K, Levine M. GATA factors participate in tissue-specific immune responses in Drosophila larvae. Proc Natl Acad Sci USA. 2006 Oct;103(43):15957-62.

16 Giannoni F, Müller HM, Vizioli J, Catteruccia F, Kafatos FC, Crisanti A. Nuclear factors bind to a conserved DNA element that modulates transcription of Anopheles gambiae trypsin genes. J Biol Chem. 2001 Jan;276(1): 700-7.

17 Fletcher JC, Thummel CS. The Drosophila E74 gene is required for the proper stageand tissue-specific transcription of ecdysone-regulated genes at the onset of metamorphosis. Development. 1995 May;121(5): 1411-21.

$18 \mathrm{Hu}$ X, Yang R, Zhang X, Chen L, Xiang X, Gong $\mathrm{C}$, et al. Molecular cloning and functional characterization of the dual oxidase (BmDuox) gene from the silkworm Bombyx mori. PLoS One. 2013 Aug;8(8):e70118.

19 Donkó A, Péterfi Z, Sum A, Leto T, Geiszt M. Dual oxidases. Philos Trans R Soc Lond B Biol Sci. 2005 Dec;360(1464):2301-8.

20 Yang HT, Yang MC, Sun JJ, Shi XZ, Zhao XF, Wang JX. Dual oxidases participate in the regulation of intestinal microbiotic homeostasis in the kuruma shrimp Marsupenaeus japonicus. Dev Comp Immunol. 2016 Jun;59:15363. 
21 Kim SH, Lee WJ. Role of DUOX in gut inflammation: lessons from Drosophila model of gut-microbiota interactions. Front Cell Infect Microbiol. 2014 Jan;3:116.

22 Kawahara T, Quinn MT, Lambeth JD. Molecular evolution of the reactive oxygen-generating NADPH oxidase (Nox/Duox) family of enzymes. BMC Evol Biol. 2007 Jul;7(1):109.

23 Bergmiller T, Ackermann M, Silander OK. Patterns of evolutionary conservation of essential genes correlate with their compensability. PLoS Genet. 2012 Jun;8(6):e1002803.

24 Neafsey DE, Christophides GK, Collins FH, Emrich SJ, Fontaine MC, Gelbart W, et al. The evolution of the Anopheles 16 genomes project. G3 (Bethesda). 2013 Jul;3(7):1191-4.

25 Kajla M, Kakani P, Choudhury TP, Kumar V, Gupta K, Dhawan R, et al. Anopheles stephensi Heme Peroxidase HPX15 Suppresses Midgut Immunity to Support Plasmodium Development. Front Immunol. 2017 Mar;8: 249.

26 Kajla M, Kakani P, Choudhury TP, Gupta K, Gupta L, Kumar S. Characterization and expression analysis of gene encoding heme peroxidase HPX15 in major Indian malaria vector Anopheles stephensi (Diptera: culicidae). Acta Trop. 2016 Jun;158:107-16.

27 Peters RS, Meusemann K, Petersen M, Mayer C, Wilbrandt J, Ziesmann T, et al. The evolutionary history of holometabolous insects inferred from transcriptome-based phylogeny and comprehensive morphological data. BMC Evol Biol. 2014 Mar;14(1):52.

28 Nijhout HF, Riddiford LM, Mirth C, Shingleton AW, Suzuki Y, Callier V. The developmental control of size in insects. Wiley Interdiscip Rev Dev Biol. 2014 Jan-Feb;3(1):11334.

29 Edens WA, Sharling L, Cheng G, Shapira R, Kinkade JM, Lee T, et al. Tyrosine cross-linking of extracellular matrix is catalyzed by Duox, a multidomain oxidase/peroxidase with homology to the phagocyte oxidase subunit gp91phox. J Cell Biol. 2001 Aug;154(4): 879-91.

30 Thein MC, Winter AD, Stepek G, McCormack G, Stapleton G, Johnstone IL, et al. Combined extracellular matrix cross-linking activity of the peroxidase MLT-7 and the dual oxidase BLI- 3 is critical for post-embryonic viability in Caenorhabditis elegans. J Biol Chem. 2009 Jun;284(26):17549-63.
31 Fletcher JC, Thummel CS. The ecdysone-inducible Broad-complex and E74 early genes interact to regulate target gene transcription and Drosophila metamorphosis. Genetics. 1995 Nov;141(3):1025-35.

32 Telang A, Frame L, Brown MR. Larval feeding duration affects ecdysteroid levels and nutritional reserves regulating pupal commitment in the yellow fever mosquito Aedes aegypti (Diptera: culicidae). J Exp Biol. 2007 Mar; 210(Pt 5):854-64.

33 Urness LD, Thummel CS. Molecular analysis of a steroid-induced regulatory hierarchy: the Drosophila E74A protein directly regulates L71-6 transcription. EMBO J. 1995 Dec; 14(24):6239-46.

34 Hagedorn HH, O'Connor JD, Fuchs MS, Sage B, Schlaeger DA, Bohm MK. The ovary as a source of alpha-ecdysone in an adult mosquito. Proc Natl Acad Sci USA. 1975 Aug;72(8): 3255-9.

35 Xiao X, Yang L, Pang X, Zhang R, Zhu Y, Wang $\mathrm{P}$, et al. A Mesh-Duox pathway regulates homeostasis in the insect gut. Nat Microbiol. 2017 Mar;2(5):17020.

36 Oliveira JH, Gonçalves RL, Lara FA, Dias FA, Gandara AC, Menna-Barreto RF, et al. Blood meal-derived heme decreases ROS levels in the midgut of Aedes aegypti and allows proliferation of intestinal microbiota. PLoS Pathog. 2011 Mar;7(3):e1001320.

37 Habtewold T, Duchateau L, Christophides GK. Flow cytometry analysis of the microbiota associated with the midguts of vector mosquitoes. Parasit Vectors. 2016 Mar;9(1):167.

38 Kajla M, Choudhury TP, Kakani P, Gupta K, Dhawan R, Gupta L, et al. Silencing of Anopheles stephensi Heme Peroxidase HPX15 Activates Diverse Immune Pathways to Regulate the Growth of Midgut Bacteria. Front Microbiol. 2016 Aug;7:1351.

39 Luckhart S, Crampton AL, Zamora R, Lieber MJ, Dos Santos PC, Peterson TM, et al. Mammalian transforming growth factor beta $1 \mathrm{ac}-$ tivated after ingestion by Anopheles stephensi modulates mosquito immunity. Infect Immun. 2003 Jun;71(6):3000-9.

40 Smith RC, Vega-Rodríguez J, Jacobs-Lorena M. The Plasmodium bottleneck: malaria parasite losses in the mosquito vector. Mem Inst Oswaldo Cruz. 2014 Aug;109(5):644-61.

41 Diaz-Albiter H, Sant'Anna MR, Genta FA, Dillon RJ. Reactive oxygen species-mediated immunity against Leishmania mexicana and Serratia marcescens in the sand phlebotomine fly Lutzomyia longipalpis. J Biol Chem. 2012 Jul;287(28):23995-4003.
42 Lodge R, Diallo TO, Descoteaux A. Leishmania donovani lipophosphoglycan blocks $\mathrm{NADPH}$ oxidase assembly at the phagosome membrane. Cell Microbiol. 2006 Dec;8(12): 1922-31.

43 Fraiture M, Baxter RH, Steinert S, Chelliah Y, Frolet C, Quispe-Tintaya W, et al. Two mosquito LRR proteins function as complement control factors in the TEP1-mediated killing of Plasmodium. Cell Host Microbe. 2009 Mar; 5(3):273-84

44 Blandin S, Shiao SH, Moita LF, Janse CJ, Waters AP, Kafatos FC, et al. Complement-like protein TEP1 is a determinant of vectorial capacity in the malaria vector Anopheles gambiae. Cell. 2004 Mar;116(5):661-70.

45 Akagi K, Ueda H. Regulatory mechanisms of ecdysone-inducible Blimp-1 encoding a transcriptional repressor that is important for the prepupal development in Drosophila. Dev Growth Differ. 2011 Jun;53(5):697-703.

46 Hurd TR, Liang FX, Lehmann R. Curly encodes dual oxidase, which acts with heme peroxidase Curly Su to shape the adult Drosophila wing. PLoS Genet. 2015 Nov;11(11):e1005625.

47 Anh NT, Nishitani M, Harada S, Yamaguchi M, Kamei K. Essential role of Duox in stabilization of Drosophila wing. J Biol Chem. 2011 Sep;286(38):33244-51.

48 Ratiu AC, Neagu A, Mihalache MR, Lazar V, Evocoiu A. Molecular and bioinformatics analysis of the relative expression profiles of dorsal, Toll-1, Relish and Duox genes in young versus old diutinus workers of Apis mellifera. Rom Biotechnol Lett. 2016;21: 11513-26.

49 Richman AM, Dimopoulos G, Seeley D, Kafatos FC. Plasmodium activates the innate immune response of Anopheles gambiae mosquitoes. EMBO J. 1997 Oct;16(20):6114-9.

50 Dimopoulos G, Seeley D, Wolf A, Kafatos FC. Malaria infection of the mosquito Anopheles gambiae activates immune-responsive genes during critical transition stages of the parasite life cycle. EMBO J. 1998 Nov;17(21):6115-23.

51 Tahar R, Boudin C, Thiery I, Bourgouin C. Immune response of Anopheles gambiae to the early sporogonic stages of the human malaria parasite Plasmodium falciparum. EMBO J. 2002 Dec;21(24):6673-80.

52 Kajla M, Gupta K, Gupta L, Kumar S. A finetuned management between physiology and immunity maintains the gut microbiota in insects. Biochem Physiol. 2015;4:182.
Mosquito Duox Is Agonistic to Plasmodium
J Innate Immun 2019;11:496-505

DOI: $10.1159 / 000497417$ 